\title{
Orbital complications of pediatric rhinosinusitis: A single institution report
}

\author{
Göksel Turhal $^{1 \oplus}$, Sercan Göde ${ }^{1 \oplus}$, Baha Sezgin $^{1 \oplus}$, İsa Kaya ${ }^{1 \oplus}$, Aykut Bozan $^{2 \oplus}$,

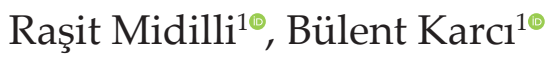 \\ ${ }^{1}$ Department of Otorhinolaryngology, Ege University Faculty of Medicine, İzmir; ${ }^{2}$ Department of Otorhinolaryngology, Medical Park \\ Tarsus, Mersin, Turkey.
}

\begin{abstract}
Background and objectives. Rhinosinusitis is one of the most common infections of childhood. Rhinosinusitis usually limits itself in the pediatric age group, however orbital and intracranial complications may arise in some of the patients. The purpose of the study was to retrospectively analyse the previous treatments and outcomes in pediatric rhinosinusitis patients with orbital complications.

Methods. The effect and prognosis of medical treatment and endoscopic sinus surgery are reported in this study. Twenty-five pediatric patients diagnosed with complicated rhinosinusitis between January 2008 February 2016 were included in the study. Orbital complications, examination findings, radiological imaging and blood counts were retrospectively collected from patient files. The duration of hospitalization, source of the infection, complications, previous medical and surgical treatments were also retrospectively assessed.
\end{abstract}

Results. Average age of the patients were $8.84 \pm 4.02$ years (range: $1-16$ years). The mean length of stay in hospital was $6.72 \pm 3.28$ days. Hospitalization in surgically treated group was higher than primarily medically treated group. However this difference could not reach to a statistically significant level ( $p>0.05)$. Mean hospitalization time was found $5.21 \pm 2.51$ and $8.43 \pm 2.87$ days in patients diagnosed with preseptal cellulitis and subperiosteal abscess respectively. Hospitalization in patients with subperiosteal abscess was higher than preseptal cellulitis and a statistically significant difference was detected $(\mathrm{p}<0.05)$.

Conclusion. Morbidity and mortality of orbital complications which are the most common complications of pediatric rhinosinusitis, could significantly be reduced by using appropriate treatment methods and an early diagnosis. Conservative therapy is an effective method for patients with preseptal cellulitis and most cases of orbital cellulitis in children.

Key words: pediatric rhinosinusitis, orbital complications, endoscopic sinus surgery, complicated rhinosinusitis, preseptal cellulitis.

Rhinosinusitis is the inflammation of the mucosal lining of paranasal sinuses and the nasal cavity. ${ }^{1}$ Rhinosinusitis usually limits itself in the pediatric age group, however orbital and intracranial complications may arise in some of the patients. ${ }^{2}$ Orbital complications

$\bigotimes$ Göksel Turhal

gokselturhal@gmail.com

Received 13th October 2017, revised 23rd January 2019, 23rd May 2019, 17th June 2019, accepted 21st June 2019.

This study was presented at the 12th Turkish Rhinology and 4th National Otology and Neurotology Congress,

21-24 April 2016, Antalya, Turkey. are classified into five groups according to the Chandler classification: preseptal cellulitis (preseptal edema or inflammatory edema), orbital cellulitis, subperiosteal abscess, orbital abscess and cavernous sinus thrombosis. ${ }^{3}$ Allergies, immunodeficiency, anatomic anomalies and ciliary dysfunction are usually associated in complicated cases. ${ }^{4}$ Early diagnosis of these complications are important in terms of reducing morbidity and mortality rate. Warning symptoms and signs of orbital complications are: inflammatory edema of the eyelids, orbital edema, exophthalmus, ophthalmoplegia, 
diplopia and decrease in the visual acuity. ${ }^{5}$ History and physical examination are adequate in most of the patients for the diagnosis of acute rhinosinusitis, however radiologic imaging is required in most of the complicated rhinosinusitis patients. ${ }^{6}$

Response to medical treatment is quite good and most of the patients can be managed with medical treatment alone., ${ }^{5,7}$ In complicated cases refractory to medical treatment, the existence of an abscess has to be considered and sought radiologically. Opthalmoplegia and deterioration of visual acuity are indications for promt surgical intervention. ${ }^{8,9}$ Timing of surgery is controversial in orbital cellulitis unresponsive to medical treatment.

The aim of this study was to retrospectively analyze previous treatments and outcomes of pediatric rhinosinusitis patients with orbital complications. Since most of the reports rely on single-institution case series, results of this study which focuses on orbital complications would guide the clinicians in treating these specific group of patients.

\section{Material and Methods}

Twenty-five pediatric rhinosinusitis patients with orbital complications between January 2008 - February 2016 were included in the study. This study was carried out at a tertiary academic center in concordance with international ethical standards and the World Health Organisation
Helsinki Declaration. It was approved by the institutional review board (Approval no: 141.1/10 - 18.02.2016- Ege University School of Medicine). Informed consent was obtained from the legal guardian in all patients.

Demographic data, orbital complications, physical examination findings, radiological imaging and laboratory results were retrospectively investigated. Diagnosis was made with clinical and laboratory findings. Duration of hospitalization, source of the infection, complications, previous medical and surgical treatments were also retrospectively assessed.

Primary purpose was obtaining clinical demographic data and treatment results, wheras the secondary purpose was the evaluation of treatment failures and assessing special concerns.

The anatomical structure of the paranasal sinuses change in the pediatric population due to the relatively rapid growth. Therefore, the patients were divided into three groups and the results were stratified based on different age groups which are given in Table I.

Patients diagnosed with preseptal or orbital cellulitis were treated with broad-spectrum antibiotics. The antibiotherapy was initiated according to the suggestion of the pediatric infectious diseases consultant. If the patients didn't show clinical and/or laboratory (decrease in leucocytosis and proinflammatory markers)

Table I. Results stratified according to different age groups.

\begin{tabular}{|c|c|c|c|c|c|c|c|c|c|}
\hline \multirow{2}{*}{ Groups } & \multirow{2}{*}{$\begin{array}{l}\text { Number } \\
\text { of } \\
\text { patients }\end{array}$} & \multirow{2}{*}{$\begin{array}{l}\text { Preseptal } \\
\text { cellulitis }\end{array}$} & \multirow{2}{*}{$\begin{array}{c}\text { Periorbital } \\
\text { cellulitis }\end{array}$} & \multirow{2}{*}{$\begin{array}{l}\text { Subperiosteal } \\
\text { abscess }\end{array}$} & \multirow{2}{*}{ Diplopia } & \multirow{2}{*}{$\begin{array}{c}\text { Mean } \\
\text { length of } \\
\text { stay in } \\
\text { hospital } \\
\text { (days) }\end{array}$} & \multicolumn{2}{|c|}{ Treatment } & \multirow{2}{*}{$\begin{array}{l}\text { Outcome } \\
\text { recurrence }\end{array}$} \\
\hline & & & & & & & Medical & $\begin{array}{c}\text { Medical + } \\
\text { Surgical }\end{array}$ & \\
\hline$<6$ years & 8 & 6 & 1 & 1 & - & 4.37 & 6 & 2 & 1 \\
\hline $\begin{array}{l}\text { Between } \\
\text { the age of } \\
6-12\end{array}$ & 11 & 7 & 1 & 3 & - & 10.27 & 7 & 4 & 1 \\
\hline >12 years & 6 & 2 & - & 3 & 1 & 4.00 & 2 & 4 & - \\
\hline Total & 25 & 15 & 2 & 7 & 1 & 7.50 & 15 & 10 & 2 \\
\hline
\end{tabular}


improvement despite a broad-spectrum antibiotics of 48-72 hours and if there was radiologically proven orbital or subperiosteal abscess, patients were treated with surgery. A computed tomography (CT) scan was performed to all patients during the first admission. The surgical procedure included endoscopic sinus surgery and drainage of the abscess.

Statistical analysis was made using computer software (SPSS version 22.0, SPSS Inc. Chicago, IL, USA). Chi-square $\left(\mathrm{X}^{2}\right)$ exact tests were used for the comparison of categorical data while Wilcoxon and Mann-Whitney $\mathrm{U}$ tests were used for the analysis of non-parametric variables based on the distribution pattern of the data. Data were expressed as "mean (standard deviation; $\mathrm{SD})$ ", percent (\%), minimum-maximum, Odds Ratio (OR); 95\% confidence interval (CI) and "median (Interquartile range; IQR)" where appropriate. $\mathrm{p}<0.05$ was considered statistically significant.

\section{Results}

Average age was $8.84 \pm 4.02$ years (range: $1-16$ years). Twelve patients (48\%) were female and 13 patients (52\%) were male. The mean followup time was $33.84 \pm 3.48$ months. The mean length of hospital stay was $6.72 \pm 3.28$ days. Fifteen patients had preseptal cellulitis (60\%), seven $(28 \%)$ had subperiosteal abscess, one
(4\%) patient had diplopia related to isolated sphenoid sinusitis and two $(8 \%)$ patients had orbital cellulitis with involvement of the infraorbital and buccal area.

Fifteen patients were treated with medical therapy only, ten patients were treated with both surgery and medical therapy. One patient with preseptal cellulitis didn't improve with medical therapy for 48 hours and endonasal endoscopic surgery was performed.

Mean length of hospital stay was $7.50 \pm 3.83$ and $6.20 \pm 2.88$ days for surgically treated and only medically treated patients respectively. Hospitalization duration was higher in patients treated with surgery compared to patients with only medical treatment $(\mathrm{p}>0.05)$. Mean hospitalization time was $5.21 \pm 2.51$ and $8.43 \pm$ 2.87 days in patients diagnosed with preseptal cellulitis and subperiosteal abscess respectively $(\mathrm{p}<0.05)$.

Thirteen $(68 \%)$ of the patients had signs of proptosis, periorbital edema and hyperemia, seven $(28 \%)$ patients had decreased visual acuity, four $(16 \%)$ patients had eyelid edema and pain and one (4\%) patient had diplopia.

Ethmoid mucocele was found in two patients who were treated with surgery. No recurrences or further complications were observed in 24 patients during the follow-up. One patient (4\%)

Table II. Findings of the patients.

\begin{tabular}{|c|c|c|c|c|c|c|}
\hline & $\begin{array}{l}\text { Mean } \\
\text { Age }\end{array}$ & $\begin{array}{c}\text { Gender } \\
(\text { Female/Male })(\%)\end{array}$ & $\begin{array}{l}\text { Medical } \\
\text { Therapy }\end{array}$ & $\begin{array}{c}\text { Medical + Surgical } \\
\text { Therapy }\end{array}$ & $\begin{array}{l}\text { Length } \\
\text { of stay in } \\
\text { hospital }\end{array}$ & $\begin{array}{c}\text { Recurrence } \\
\text { (number of } \\
\text { patient) }\end{array}$ \\
\hline $\begin{array}{l}\text { Preseptal } \\
\text { cellulitis(60\%) }\end{array}$ & 8.06 & $7(28 \%) / 8(32 \%)$ & 15 & - & 5.21 & 1 \\
\hline $\begin{array}{l}\text { Periorbital } \\
\text { cellulitis( }(8 \%)\end{array}$ & 12.5 & $0 / 2(8 \%)$ & - & $\begin{array}{c}2 \text { (endoscopic } \\
\text { sphenoethmoidectomy) }\end{array}$ & 5.00 & - \\
\hline $\begin{array}{l}\text { Subperiosteal } \\
\text { abscess }(28 \%)\end{array}$ & 8.42 & $4(16 \%) / 3(12 \%)$ & - & $\begin{array}{l}7 \text { (endoscopic } \\
\text { sphenoethmoidectomy }+ \\
\text { orbital decompression) }\end{array}$ & 8.43 & 1 \\
\hline $\begin{array}{l}\text { Diplopia with } \\
\text { isolated sphenoid } \\
\text { sinusitis }(4 \%)\end{array}$ & 16 & $1(4 \%) / 0$ & - & 1 (optic decompression) & 3.00 & - \\
\hline Total $(100 \%)$ & 8.84 & $12(48 \%) / 13(52 \%)$ & $15(60 \%)$ & $10(40 \%)$ & 6.72 & 2 \\
\hline
\end{tabular}


had recurrence and required additional surgery two years after the initial treatment. The patients with mucoceles didn't describe any history of trauma or prior surgery. Comparison of the patients' findings regarding orbital complications are shown in Table II.

Nine $(36 \%)$ of the patients were treated with ceftriaxone, 11 patients (44\%) were treated with ceftriaxone and metronidazole, 3 patients $(12 \%)$ with ampicillin and sulbactam, 1 patient (4\%) with vancomisin and ceftriaxone and 1 patient $(4 \%)$ with meropenem. The administration of antibiotherapy was started on the first day and mean length of medical therapy was 7.50 days. All patients were discharged with an oral antibiotic therapy after at least 7 days.

All patients who were treated with surgery underwent functional endoscopic endonasal sinus surgery. Patients who had orbital or subperiosteal abscess underwent orbital decompression and abscess drainage, whereas patients with deterioration of the vision underwent both orbital and optic decompressions. One patient required external abscess drainage in addition to the endonasal treatment (Fig. 1). Surgical treatment was comprised of one opticnervedecompression, two endoscopic sphenoethmoidectomies and seven endoscopic sphenoethmoidectomies+orbital decompressions. None of the patient's paranasal sinus bacterial cultures revealed any microbiological agents.

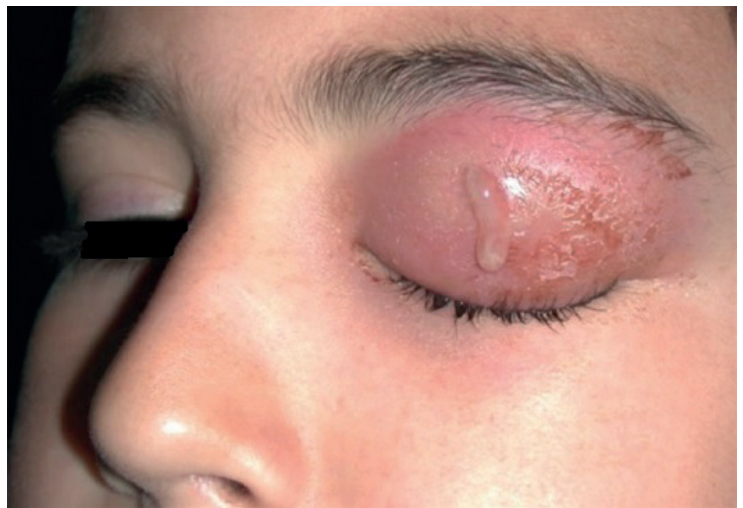

Fig. 1. Preoperitve photo of a 6-year-old girl with orbital abscess requiring external drainage.

\section{Dicussion}

Acute rhinosinusitis is a relatively frequent disease of the childhood. The reported incidence of orbital complications is $6 \%$ in a retrospective report. ${ }^{10}$ The most frequent orbital complication in this study was preseptal cellulitis $(60 \%)$ followed by subperiosteal abscess $(28 \%)$ which is similar with previous studies. ${ }^{11,12}$ Because most orbital complications are managed successfully with medical therapy alone, it has been suggested that patients with 1st and 2nd stage orbital complications can be treated with broad-spectrum antibiotics alone. However it is generally accepted that surgical intervention is necessary in patients unresponsive to medical therapy within 48 hours despite broad-spectrum antibiotics, documented subperiosteal or intraorbital abcess and reduced visual acuity or color vision. ${ }^{13,14}$ Some authors suggest waiting 48-72 hours with medical therapy alone if the vision is normal in case of a subperiosteal abscess. $^{8}$

According to Oxford et al. ${ }^{15}$, the most common isolated organism was Streptococcus milleri in 7 of the 23 patients with subperiosteal orbital abscess. Hwang et al. $^{16}$ reported that streptococcus viridans was the most common isolated agent in complicated pediatric rhinosinusitis. Devrim et al. ${ }^{17}$ reported that most common isolated organism was Staphylococcus auerus (41.9\%) followed by coagulase-negative staphylococcus $(25.8 \%)$ and Haemophilus influenza type b $(6 \%)$ in orbital and preseptal sellulitis patients. Culture of the offending organism should be made whenever possible because it will guide the antibioterapy. However all of the patients had negative bacterial culture results. All patents were on oral antibiotics before admission, thus negative culture was an expected outcome. Stokken et al. $^{18}$ reported no growth (30.8\%), Streptococcus milleri (30.8\%), and normal flora $(19.2 \%)$ in complicated pediatric acute bacterial rhinosinusitis patients. In general etiological agents could be identified in only 20-30\% of the cases so treatment is usually initiated empirically. 
In this study, 15 patients with preseptal cellulitis and two patients with orbital cellulitis were treated with medical treatment alone, however two of these patients with orbital cellulitis didn't respond to medical therapy and were treated with surgery. One of these two patients developed ophthalmoplegia and decrease in visual acuity preoperatively. Patients treated with medical therapy and patients treated with surgery after failed medical therapy healed well without any morbidity.

Patients with stage 1 and 2 orbital complications must be closely monitored for voluntary eye movements and visual acuity before proceeding with surgery. Orbital decompression is suggested in patients with proven abscess in CT scans. ${ }^{15}$ Drainage and orbital decompression using the endonasal endoscopic approach was applied on 7 patients with CT proven subperiosteal abscess (Fig. 2). Abscess drainge via an external approach was applied in one of these patients because the patient was not improving following postoperative second week (Fig. 1). In the case of a proven abscess in contrast enhanced CT, the preferred treatment method is abscess drainage via an endonasal endoscopic approach. External approach or combined endonasal and external approaches could be used in necessary cases. The recent advances in endoscopic visualization has significantly decreased the need for external approaches. In the case of frontal sinusitis, external approaches may be necessary. Indications for these procedure includes disease related to a type 4 frontal cell. Infections that reach subcutaneous tissue could also be treated with an external approach. Many authors suggest removing the anterior ethmoid cells and lamina papyracea for the drainage of subperiosteal abscess is adequate. ${ }^{16}$ Hospitalization time was related with the type of treatment and complication. Patients who were treated both surgically and medically with subperiosteal and orbital abscess were hospitalized significantly longer than patients with preseptal cellulitis. Caglar et al. ${ }^{19}$ analysed treatment costs of pediatric preseptal cellulitis cases in 54 patients and reported that sinusitis was associated with longer length of stay and higer hospital costs.

Rhinosinusitis with orbital complications accompanied with ethmoid mucoceles constitute a specific group that needs to be handled separately. One of the patient in this study developed recurrent orbital cellulitis and this patient had an ethmoid mucocele which was not apparent at the first admission, but was clearly visible during the second admission. The patient was diagnosed with left preseptal cellulitis at the first admission and full recovery was achieved with intravenous $100 \mathrm{mg} / \mathrm{kg} /$ day ceftriaxone treatment. After two years, the patient was again diagnosed with a right etmoid mucocele with subperiosteal abscess

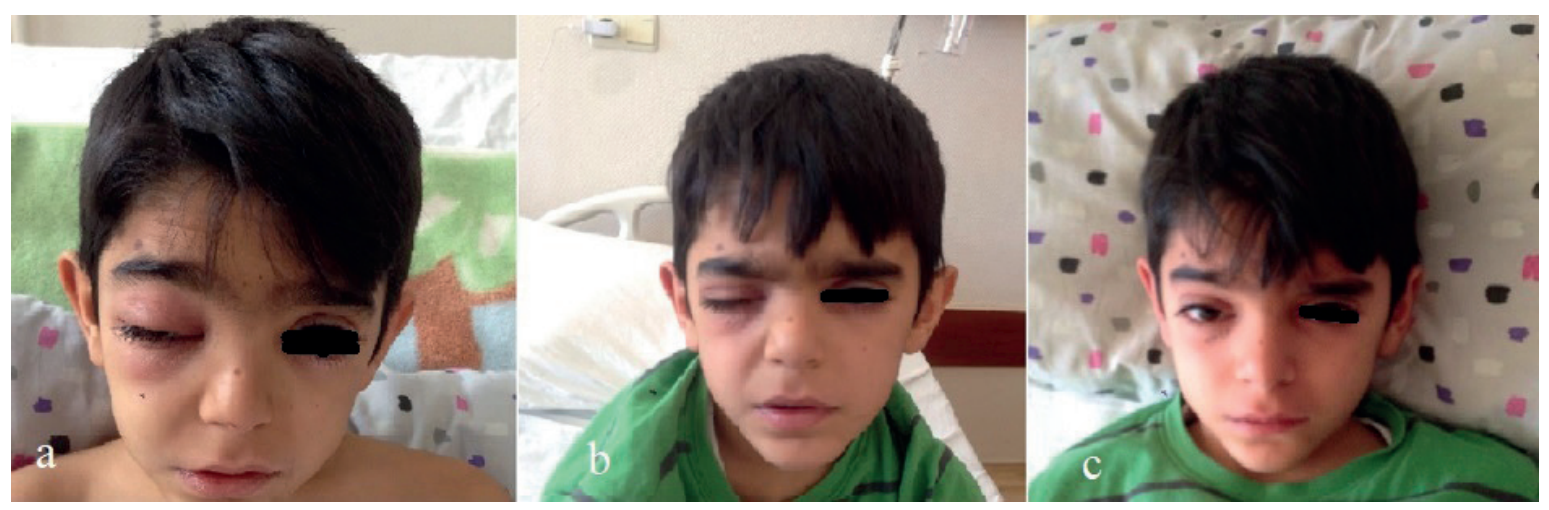

Fig. 2. Preoperative and postoperative photos of a 7-year-old boy with subperiosteal abscess after endoscopic endonasal orbital decompression and broad-spectrum antibiotics (a: preoperative, b: postoperative 2nd day, c: postoperative 4 th day). 
and required surgery. Endonasal endoscopic surgery (orbital decompression and drainage of the abscess) was performed. Because of recurrent complicated sinusitis, the patient was consulted to pediatric immunology clinic. Addition to the complicated sinusitis, the patient also had recurrent episodes of pneumonia and gastroinstesinal infections. The patient than was diagnosed with IgG deficency and is regularly treated with intravenous immunoglobulin (Figs. 3 and 4). No predisposing underlying medical issues were present in the other patients. Immunological work up could be performed in recurrent complicated pediatric rhinosinusitis cases. One has to be careful about ethmoid mucoceles especially in recurrent cases and have a low threshold for surgery even in patients with stage 1 orbital complications with ethmoid mucoceles. Although lack of evidence regarding the relation between immunodefficiency and recurrent sinusitis, it should be kept in mind that immunodeficiency might be found in cases of recurrent pediatric rhinosinusitis and their orbital complications as in the aformentioned patient.

We gathered our treatment algorithm in Fig. 5. After diagnosis patients are classified according to the Chandler's classification system. In the presence of abscess surgical therapy is almost totally implemented. In the presence of preseptal or orbital cellulitis medical therapy
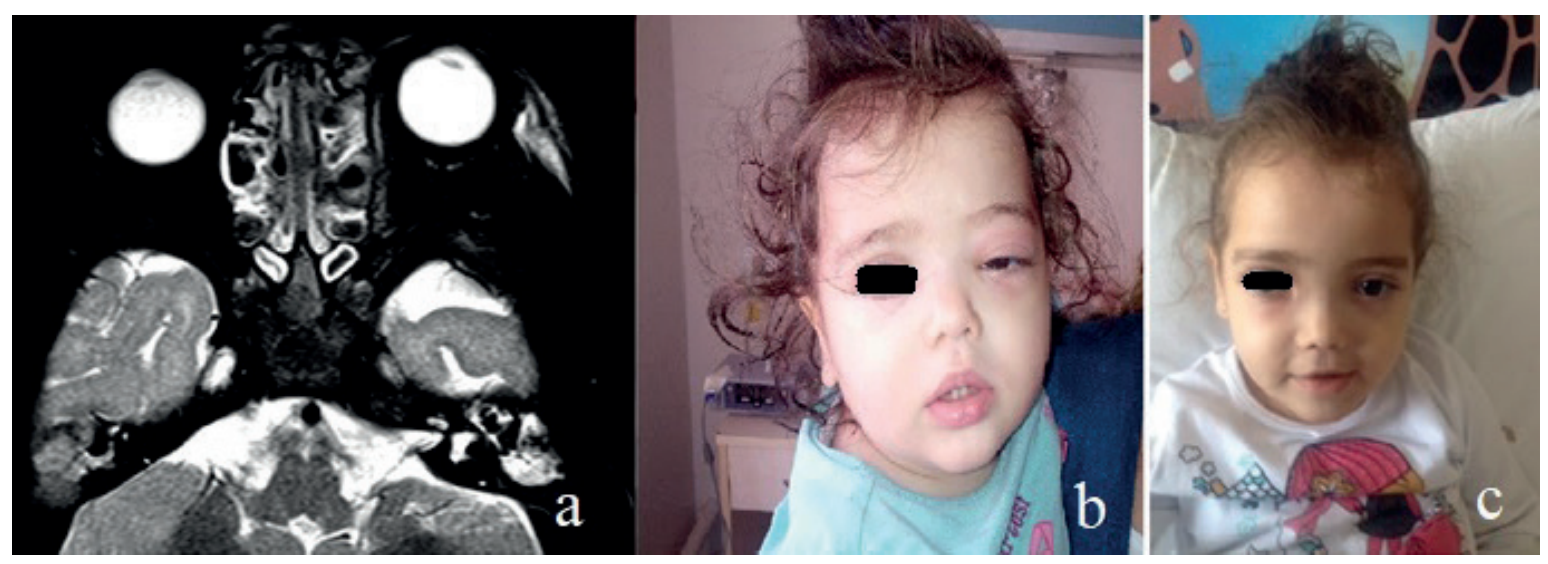

Fig. 3. MRI and photos of one year-old-girl diagnosed with left sided preseptal cellulitis in first admission (a: pretreatment MRI, b: pretreatment photo, c: The 6th day of treatment).

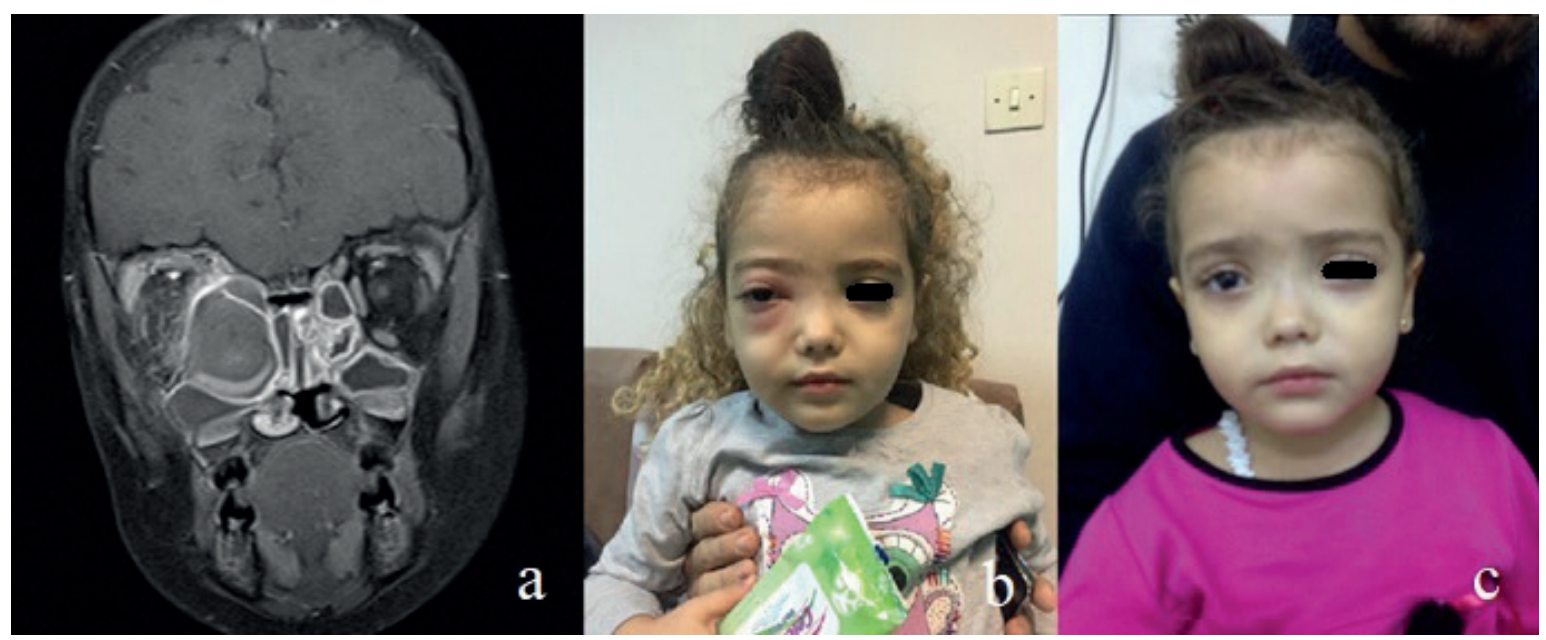

Fig. 4. Same girl's MRI of 3-year-old girl diagnosed with right sided ethmoid mucocele in second admission (two years later) (a: preoperative MRI, b: postoperative first day, c: postoperative 4th day). 


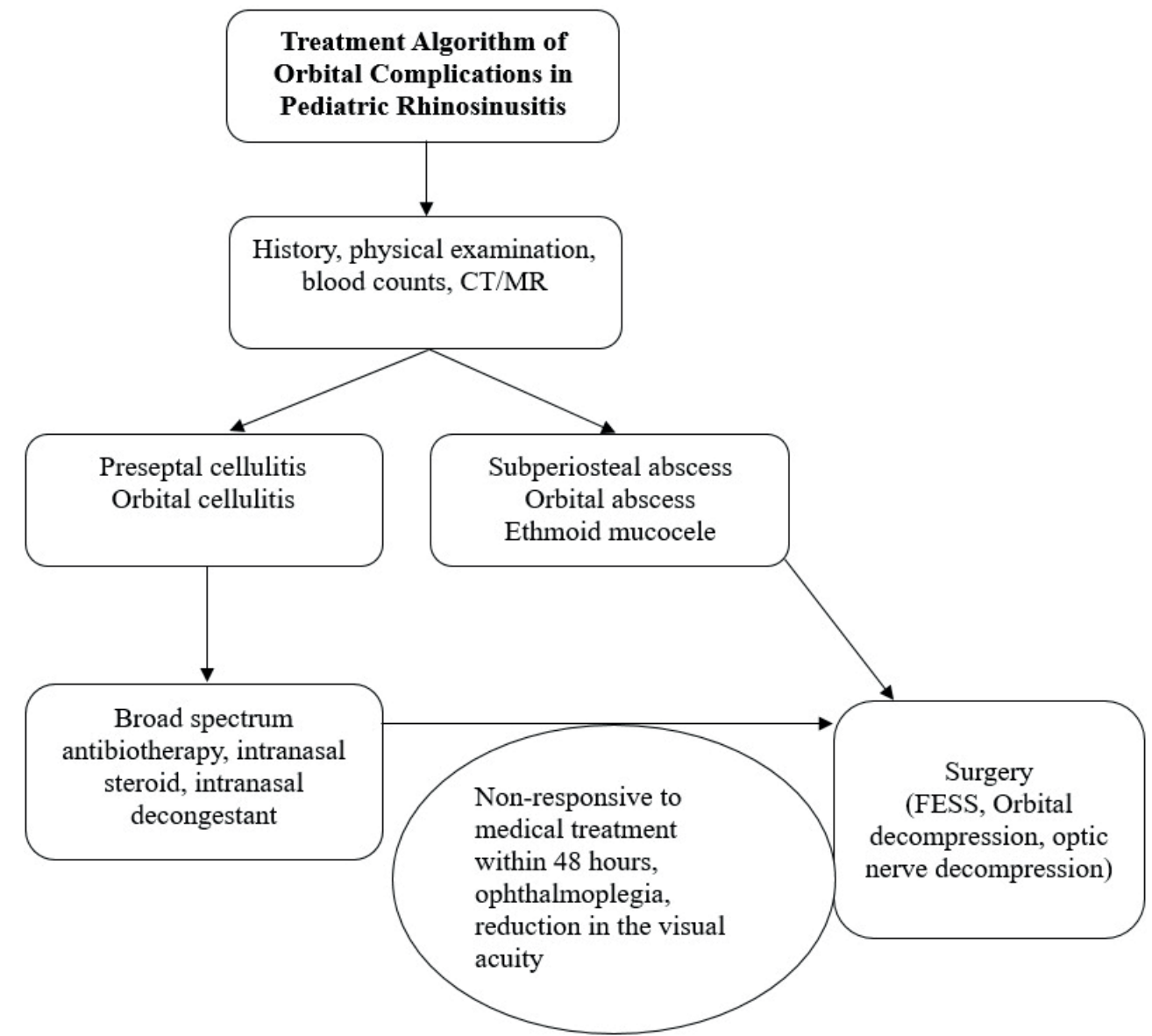

Fig. 5. Treatment algorithm regarding acute rhinosinusitis of pediatric patients with orbital complications.

is initiated. If the patient is non-responsive to medical therapy, if there is opthalmoplegia or decrease in visual acuity surgical therapy is required.

Morbidity and mortality of orbital complications could significantly be reduced by using appropriate treatment methods and an prompt diagnosis. With reference to the results of this study medical therapy was sufficent in group 1 and 2 patients. Additionally eventhough medical therapy responsive subperiosteal abscesses are amenable to medical therapy, most radiologically proven abscesses require surgical intervention especially when there is loss in vision, limitation in ocular movement or unresponsiveness to aggressive medical therapy. As in the recurrent case, eventhough ethmoid mucoceles accompany only a small percentage of patients with preseptal edema, surgical treatment needs to be considered especially in recurrent cases. It is suggested that patients with chronic or recurrent infections and complications should undergo further investigation of their immunological status as the patient with $\operatorname{IgG}$ deficiency in this study. We hope findings of this study might help and guide both otolaryngologists and pediatricians managing this serious complication of rhinosinusitis.

\section{REFERENCES}

1. Fokkens WJ, Lund VJ, Mullol J, et al. EPOS 2012: European position paper on rhinosinusitis and nasal polyps 2012. A summary for otorhinolaryngologists. Rhinology 2012; 50: 1-12.

2. Badr DT, Gaffin JM, Phipatanakul W. Pediatric rhinosinusitis. Curtreat Options Allergy 2016; 3: 268-281. 
3. Chandler JR, Langenbruner DJ, Stevens ER. The pathogenesis of orbital complications in acute sinusitis. Laryngoscope 1970; 80: 1414-1428.

4. Brook I, Friedman EM, Rodriguez WJ, Controni G. Complications of sinusitis in children. Pediatrics 1980; 66: 568-572.

5. Sciarretta V, Demattè M, Farneti P, et al. Management of orbital cellulitis and subperiosteal orbital abscess in pediatric patients: a ten-year review. Int J Pediatr Otorhinolaryngol 2017; 96: 72-76.

6. Oxford LE, McClay J. Complications of acute sinusitis in children. Otolaryngol Head Neck Surg 2005; 133: 32-37.

7. Williams SR, Carruth JA. Orbital infection secondary to sinusitis in children: diagnosis and management. Clin Otolaryngol Allied Sci 1992; 17: 550-557.

8. Bhargava D, Sankhla D, Ganesan A, Chand P. Endoscopic sinus surgery for orbital subperiosteal abscess secondary to sinusitis. Rhinology 2001; 39: 151-155.

9. Eviatar E, Gavriel H, Pitaro K, Vaiman M, Goldman M, Kessler A. Conservative treatment in rhinosinusitis orbital complications in children aged 2 years and younger. Rhinology 2008; 46: 334-337.

10. Mekhitarian Neto L, Pignatari S, Mitsuda S, Fava AS, Stamm A. Acute sinusitis in children: a retrospective study of orbital complications. Braz J Otorhinolaryngol 2007; 73: 75-79.

11. Zeifer B. Pediatric sinonasal imaging: normal anatomy and inflammatory disease. Neuroimag Clin N Am 2000; 10: 137-159.
12. Souliere CR Jr, Antoine GA, Martin MP, Blumberg $\mathrm{AI}$, Isaacson G. Selective non-surgical management of subperiosteal abscess of the orbit: computerized tomography and clinical course as indication for surgical drainage. Int J Pediatr Otorhinolaryngol 1990; 19: 109-119.

13. Benninger MS, Stokken JK. Acute rhinosinusitis: pathogenesis, treatment and complications. In: Flint PW, Haughey BH, Lund V, Niparko JK, Robbins TK, Thomas JR, Lesperance MM(eds). Cummings Otolaryngology Head and Neck Surgery (6th ed). Philadelphia: Elsevier Saunders, 2015: 724-730.

14. Siedek V, Kremer A, Betz CS, Tschiesner U, Berghaus A, Leunig A. Management of orbital complications due to rhinosinusitis. Eur Arch Otorhinolaryngol 2010; 267: 1881-1886.

15. Oxford LE, McClay J. Medical and surgical management of subperiosteal orbital abscess secondary to acute sinusitis in children. Int J Pediatr Otorhinolaryngol 2006; 70: 1853-1861.

16. Hwang SY, Tan KK. Streptococcus viridans has a leading role in rhinosinusitis complications. Ann Otol Rhinol Laryngol 2007; 116: 381-385.

17. Devrim I, Kanra G, Kara A, et al. Preseptal and orbital cellulitis: 15-year experience with sulbactam ampicillin treatment. Turk J Pediatr 2008; 50: 214218.

18. Stokken J, Gupta A, Krakovitz P, Anne S. Rhinosinusitis in children: a comparison of patients requiring surgery for acute complications versus chronic disease. Am J Otolaryngol 2014; 35: 641-646.

19. Çağlar İ, Kafes C, Korcum M, et al. Hospital cost analysis of children with preseptal cellulitis. Int J Pediatr Otorhinolaryngol 2018; 106: 96-99. 